\title{
The Many Functions of Hand Gestures While Communicating Spatial Ideas An Empirical Case Study
}

\author{
> Sema Alaçam \\ Istanbul Technical University, TURKEY \\ Semosphereqgmail.com
}

\begin{abstract}
Physical dimensions of the designing activity these representations will probably exist Architects substantially develop their ideas in space through a visual apprehension of spatial relations. We aim to explore how hand gestures play role in presenting geometric features, spatial relations and ideas through a qualitative evaluation of an empirical case study. (100 words)
\end{abstract}

Keywords: Architectural design environments; Hand gestures; Iconic gestures; Spatial thinking.

\section{Introduction}

The past two decades have seen the emergence of several computational approaches to the architectural design process, building on theoretical discussions that date back to over a half century ago. Apropos approaches diverging from traditional representations such as scaled models and drawings, the first paperless design studio attempt goes back to the early 1990s. While novel computational approaches have expanded the domain of architectural knowledge, standard approaches like sketching and physical model making still dominate architecture education. There is a large body of research that has examined the relationship between the designer and her design environments from the perspective of artefacts and how these influence designers' way of thinking. In order to understand why traditional ways of designing have maintained their importance in architecture education, one has to look beyond the object/representation's point of view and also carefully analyze the affected subject's perspective. With this in mind, we argue that hands play important roles in perceiving space, recalling spatial information and translating spatial relations into other contexts. I therefore aim to contribute to the discussions on architects' way of interacting with digital media through a phenomenological approach. No singular methodology or point of view suffices to gain a comprehensive insight into this complex issue. Further, I believe that holistic ways of approaching the mind-body and thought-experience interrelations are to be adopted in place of dualistic ones. The importance of studying hand gestures, further, lies in that they are usually used unconsciously while making connections between past experiences and actual actions in a spatial way.

\section{Sensory Foundations of Spatial Thinking}

Recent research in neuroscience suggests that spatial tasks are executed in more complex relations than was previously assumed, via multiple, distributed areas of the brain and using complex connecting circuits (Millar, 2006). Therefore it is extremely difficult to evaluate the impact of each modality separately (such as tactile, visual, etc). On the other hand, "touch" and "movement" can be considered as an important basis of spatial coding where hand gestures play a fundamental part (Millar, 2006). In addition, hand gestures both guide and govern meaning making during interactions with artefacts and convey non-verbal, spatial knowledge. Using the gestural taxonomy of McNeill, Gulberg (1999) designs an experimental setup with two participants, where one of the participant was asked to look at a 2D stimulus image of a narration and describe it; the second participant was asked to the draw based upon this description(Gulberg, 1999). Gulberg (1999) reports that even through there was no clear structure to the speech and thought the drawer could see the narrator, the "deictic" gestures played an important role in mapping spatial relations explicitly, revealing spatial orientation and directions of the given 2D image (Gulberg, 1999). In addition, gestures helped understand dynamic concepts, motion and action in a more effective way (Kang, et at., 2012). Trafton et al. (2006) examine how spatial language can be gestured and which spatial aspects affect iconic gesture production (Trafton, 2006). Golledge (1995) proposes four spatial primitives: identity, location/relation, magnitude and time in respect to the relation between human 
cognition and spatial language (Golledge, 1995; Trafton et al., 2006). The term "spatial relationship" was used by Ekman and Friesen (1969) to denote "On which the movement indicates distance between people, objects, ideas" (Ekman and Friesen, 1969: 62). In this sense, the term is also intimately related to abstract and conceptual ideas as well, apart from the location of physical object in the space. In addition to these, as a reflection of gesture studies in the domain of architecture, there exists few studies in this matter (for an historical overview see: Visser and Maher, 2011). Borodistky (2000) and Borodistky et al. (2001) propose that abstract conceptual domains are structured through metaphorical mappings of experience and that the perception of time is related to experience as well (Borodistky, 2000; Borodistky et al., 2001). Regier and Carlson (2001) demonstrate the constitution of spatial expressions in six different languages and concluded that they are all based on bodily experience (Regier and Carlson, 2001).

\section{Gesticulation of Thought}

"Architecture is also a product of the knowing hand. The hand grasps the physicality and materiality of thought and turns it into a concrete image" (Pallasmaa, 2009:16).

McNeill (1992) classifies gestures under four main groups:

- Iconic,

- Metaphoric,

- Deictic,

- $\quad$ Beats (McNeill, 1992).

The term "iconic gesture" was first defined by McNeill and Levi in 1982 (McNeill and Levi, 1982). Iconic gestures are considered to involve pictorial correlation between the gesture and the shape in the space. They express concrete beings and/or actions and convey semantic content that has a formal or pictorial representation (McNeill, 1996; McNeill, 2005). Metaphoric gestures address the gestural representation of abstract concepts. Beats gestures represents the binary situations (McNeill, 1996; McNeill,2005). The iconic gestures include the "kinetographic" and "pictographic" categories suggested by Ekman and Friesen (1972) (Ekman and Friesen, 1972; McNeill, 1992). Metaphoric gestures differ from iconic gestures in expressing semantic content that refers to abstract concepts, memories or thoughts (McNeill, 1992). The term "deictic gesture" refer to those involve pointing to a certain place in an area using the index finger (McNeill, 1992). Although deictic gestures are the ones which is learned first during the childhood period, in adults, they are used more often to point to abstract concepts rather than entities in a physical environment (McNeill, 2005). McNeill adds that such abstract deictic gestures are to be considered a sub-group of metaphorical gestures (McNeill, 2005). Beats gestures are used while breaking down a verbal narration into pieces (McNeill, 2005).

\section{Case Study}

A half hour physical modelling exercise involving two participants, an architect and a non-architect was designed as a case study. The case study ended up lasting thirty eight minutes in total. In order to avoid interference from their natural behavior, the participants were not informed about the methodology of the research before the exercise. The non-architect participant was asked to describe a given chair model by looking a photograph of it (Figure 1a); the architect was asked to make a scaled physical model of the same chair (Figure 1b).

The architect (Figure 2, on the left) expected to make a physical model was not allowed to see the $2 \mathrm{D}$ photo of the chair. A video record of modeling session was used as a source of data for capturing the gestures. During the exercise, participants were seated around a table-top (horizontal plane) environment (Figure 2 ). The gestures of Participant 1, who described the model, were subsequently analyzed.

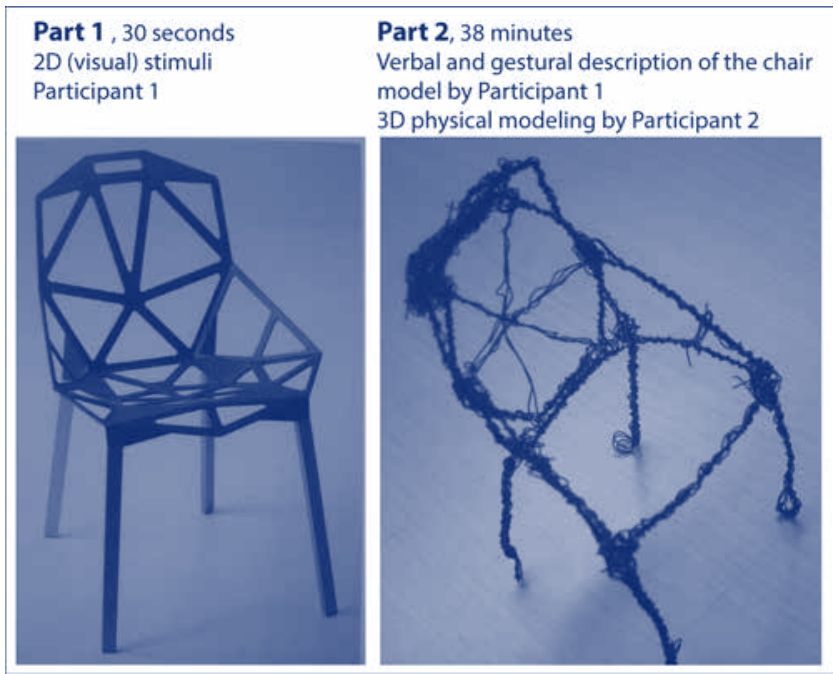

Figure la.: The picture of the object shown to Participant 1 (Url-1); Figure 1b.: 3D wiremodel of the object made by Participant 2 based on verbal and gestural descriptions of Participant 1.

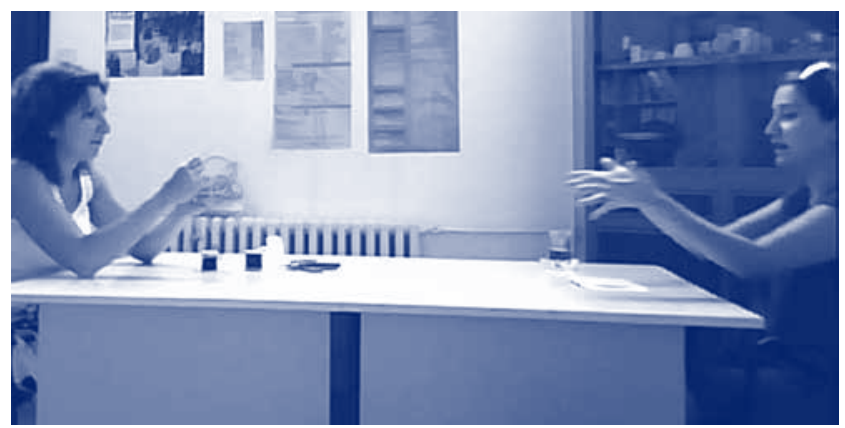

Figure 2.: A photo of the experiment setup

\section{Findings}

We observed that Participant 1, who described the chair model, used mostly iconic gestures with deictic gestures the second most frequently used gestures. Based on the relation between the gestures and their relation with the space, four categories were defined (Table 1). 


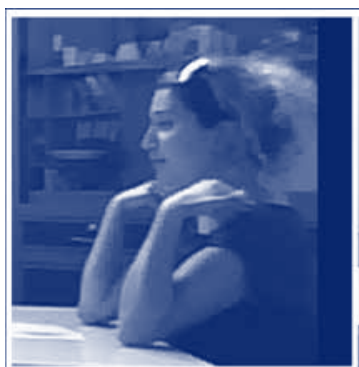

a Reference of the gesture: Body
Verbal code: "Backrest of the chair" Verbal code: "Backrest
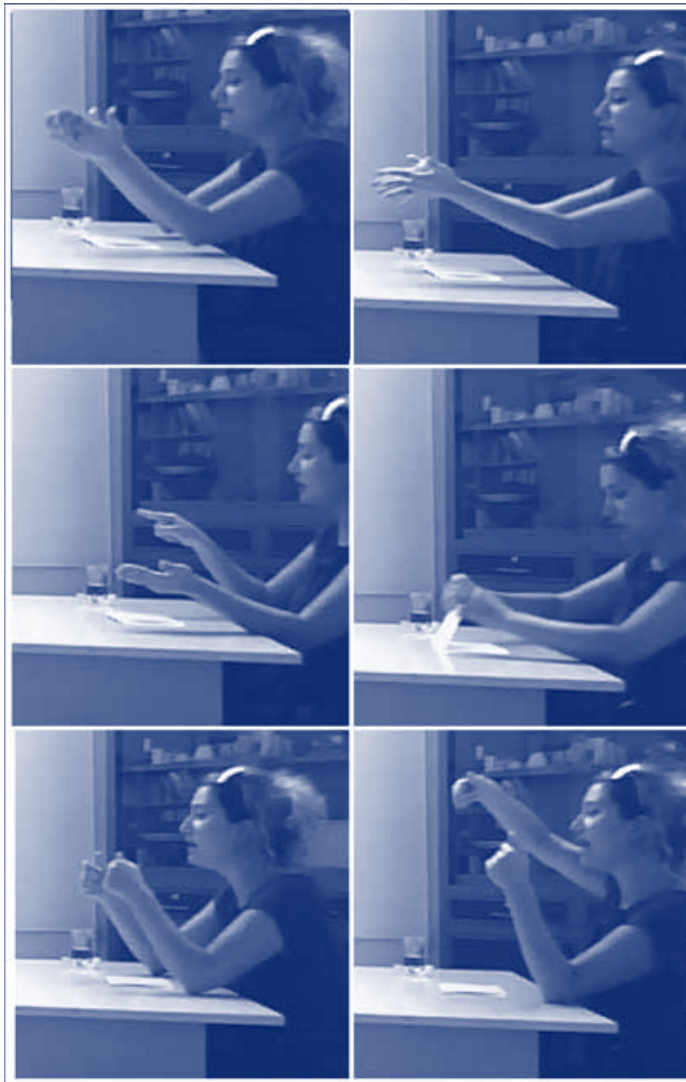

Table 1: Analysis of the relationship between the gestures and the space

\begin{tabular}{l|l|l|}
\hline $\begin{array}{l}\text { Focus of the } \\
\text { gestural expression }\end{array}$ & \multicolumn{1}{l|}{$\begin{array}{l}\text { Type of the } \\
\text { gesture }\end{array}$} \\
\hline Body & Hand and global space & Iconic \\
\hline Physical model & Hand and model space & Deictic \\
\hline Tabletop & Hand and local space & Iconic \\
\hline Abstract space & Hand and global space & Metaphoric \\
\hline
\end{tabular}

These categories of the focus are: body, physical model, table top and the abstract space. The tabletop category overlaps with abstract space, when metaphoric gestures are executed. Firstly, Participant 2 took her own body as a reference and described the parts of the chair as she was sitting on. Secondly, she pointed out the physical model that has been made by Participant 2. Finally, she used her gestures on the tabletop to define the details of the geometry. One
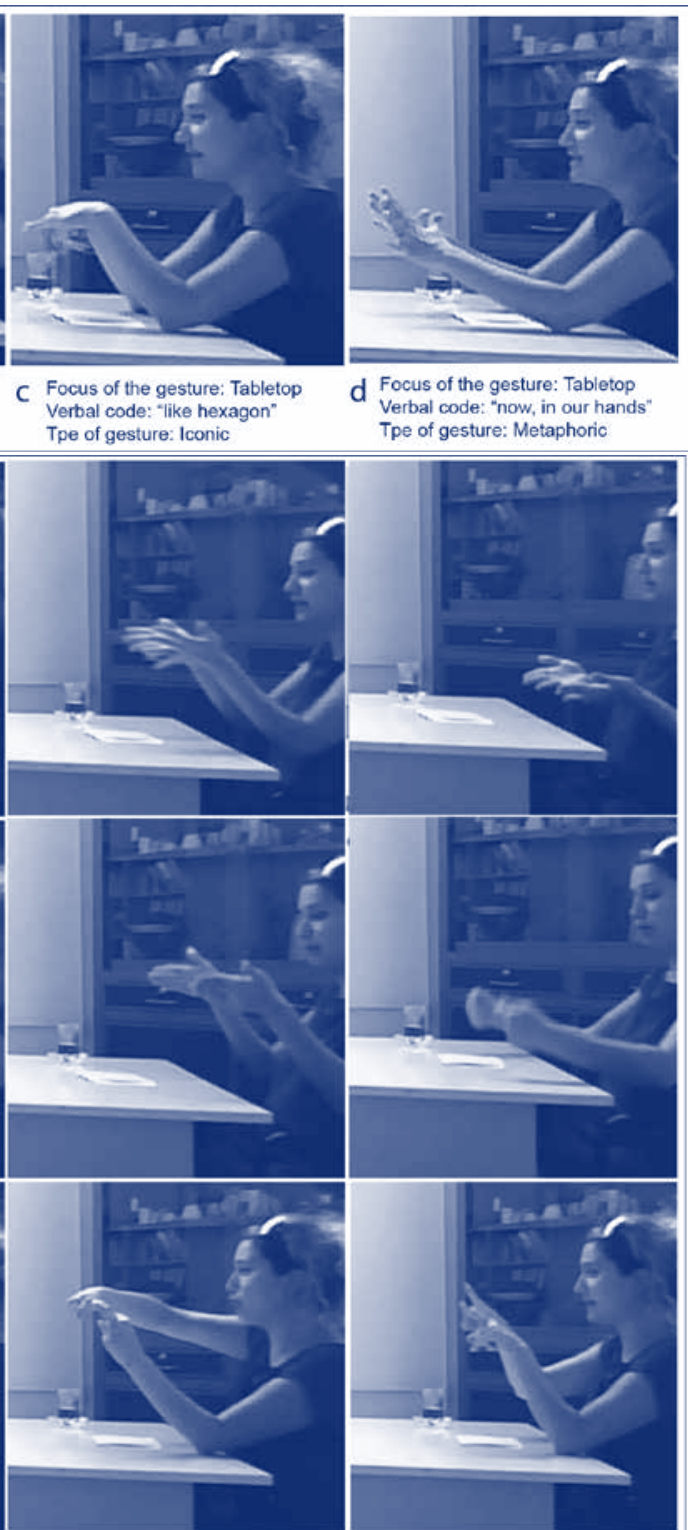

Figure 3: Basic relation type between the gestures and the space. Figure 4.: Examples from the gestures.

of the initial findings is that during the expression of the design ideas, there are clear jumps from one focus to another (Table 1).

A second finding is that, once Participant 1 described the chair in the air, above the table by her iconic gestures, she then gave references to the same abstract chair geometry. For example she simulated the hexagonal contour line in the air and later (after a few minutes) pointed to the sides of the chair and went on using the same "hanged" invisible chair model. This allowed the Participant to communicate with her own assumptions embedded in the space. In other words, it provided a kind of iterative dialogue with her own thoughts.

Iconic gestures complement the verbal dialogue when the relationship between the components of a physical model and the 
spatial information is being conveyed. They convey an important amount of data of augmented meaning of orientation, direction, angle, geometric details, sequentiality, continuity and etc. (Table 2) In the context of comparison of focus and the type of the gesture (Table 1), it was observed that, tabletop category mainly correlates with iconic gestures.

In addition to these, in a previous study analyzing student presentations, Alaçam et al (2014) introduced the following situations in terms of comparison of gestural and verbal expressions:

a. Shifted Meaning: The meaning of a gesture indicates either a backward or a forward action.

b. Augmented Gestures: The meaning of gestural expression carries more message than the correlated verbal expression. (Alaçam et al., 2014).

Similarly, in this study, it was seen that iconic gestures are the ones which carry more important messages concerning the spatial relations of the geometry. Some of the augmentation in the meaning by iconic gestures are shown in Table 2 .

Table 2: Some selected verbal content and spatial augmentation of the corresponding iconic gestures.

\begin{tabular}{|c|c|}
\hline Verbal content & Spatial qualities that gestures provide \\
\hline "Hexagon" & $\begin{array}{l}\text { Segmentation } \\
\text { Angle of the surfaces } \\
\text { Geometry } \\
\text { Direction } \\
\text { Proportions }\end{array}$ \\
\hline "Center of hexagon" & $\begin{array}{l}\text { Center } \\
\text { Center's being in the lower part of the chair }\end{array}$ \\
\hline "Triangle" & Triangle in the middle \\
\hline "Opposite sites" & Spatial relationship \\
\hline "More tilted" & $\begin{array}{l}\text { Direction } \\
\text { Angle } \\
\text { From top through low part }\end{array}$ \\
\hline
\end{tabular}

\section{Concluding Remarks}

This study can be considered as a preliminary step to understand basic qualities of hand gestures and the role they play in the embodiment of spatial thoughts by mediating between action and thought, the digital and the analog.

Based on my observations and the findings of the case study, I argue that hand gestures play an important aesthetic quality of the physical environment in that they provide a flexibility, allowing for intuitive jumps between different foci and scales. In other words, providing flexibility in the transition of the focus of the gestures might be an important property for future digital design environments.

\section{Acknowledgments}

This research is partially supported by Scientific Research Project Foundation of Istanbul Technical University under project number "34547" and by Graduate Scholarship of The Scientific and Technical Research Council of Turkey (TÜBİTAK). The author would like to thank to Prof. Dr. Gülen Çağdaş and Dr. Toni Kotnik for their constructive critiques and invaluable contributions to the doctoral research that this paper is conducted.

\section{References}

Alaçam, S., Çağdaş, G., Kotnik, T., (2014). "Exploring the role of Bodily Experience in Spatial Thinking during the Architectural Design Process", TEI 2014: 8th International Conference on Tangible, Embedded and Embodied Interaction, Ludwig-Maximilians University, Munich.

Boroditsky, C., (2000), Metaphoric Structuring Understanding Time Through Spatial Metaphors, Cognition, 75:1-28

Boroditsky, L., Ramscar, M., Frank, M. C., (2001) The Roles of Body and Mind in Abstract Thought, Proceedings of the 23rd Annual Meeting of the Cognitive Science Society.

Ekman, P., \& Friesen, W. V. (1969). The repertoire of nonverbal behavior. Semiotica, 1, 49-98.

Elia, I., Gagatsis, A., \& van den Heuvel-Panhuizen, M. (2014). The role of gestures in making connections between space and shape aspects and their verbal representations in the early years: findings from a case study. Mathematics Education Research Journal, 1-27

Emmorey, K., \& Casey, S. (2002). Gesture, thought, and spatial language. In Spatial Language, 87-101. Springer Netherlands.

Gullberg, M. (1999). Gestures in spatial descriptions. Lund Working Papers in Linguistics, 47, 87-97.

Kang, S., Tversky, B., \& Black, J. B. (2012). From hands to minds: How gestures promote action understanding. In Proceedings of the 34th Annual Conference of the Cognitive Science Society, 551-557.

McNeill, D. (1992). Hand and mind: What gestures reveal about thought. University of Chicago Press.

Pallasmaa, J. (2009). The thinking hand: Existential and embodied wisdom in architecture. Chichester: Wiley.

Regier, T., and Carlson, L. A., (2001) Grounding spatial language in perception: an empirical and computational investigation. Journal of Experimental Psychology: General, 130(2), 273.

Shih, N. J., \& Shih, W. D. (1996). Gesture modeling for architectural design.Computers \& graphics, 20(6), 849-862.

Trafton, J. G., Trickett, S. B., Stitzlein, C. A., Saner, L., Schunn, C. D., \& Kirschenbaum, S. S. (2006). The relationship between spatial transformations and iconic gestures. Spatial Cognition and Computation, 6(1), 1-29.

Tversky, B. (1999). "Spatial schemes in depictions," in Merideth Gattis (ed.) Spatial Schemas and Abstract Thought. Cambridge, MA: MIT Press, 9-112.

Url-1: Stacking Chair by Konstantin Grcic. Retrieved from www. magisdesign.com

Visser, W. (2009). The function of gesture in an architectural design meeting (ch. 15). In J. McDonnell \& P. Lloyd (Eds.), R. Luck, F. Reid, \& N. Cross (Ass. Eds.), About: Designing. Analysing design meetings (pp. 269-284). London: Taylor \& Francis.

Visser, W., \& Maher, M. L. (2011). The role of gesture in designing. AI EDAM-Artificial Intelligence Engineering Design Analysis and Manufacturing, 25(3), 213. 